\title{
Economic Evaluation of Flexible IGCC Plants with Integrated Membrane Reactor Modules
}

\author{
Juzheng Zhang, Michel-Alexandre Cardin, Nikolaos Kazantzis \\ Simon K. K. Ng and Y. H. Ma, Fellow, AIChE
}

\begin{abstract}
Integrated Gasification Combined Cycle with embedded membrane reactor modules (IGCC-MR) represents a new technology option for the co-production of electricity and pure hydrogen endowed with enhanced environmental performance capacity. It is an alternative to conventional coaland gas-fired power generation technologies. As a new technology, the IGCC-MR power plant needs to be evaluated in the presence of irreducible regulatory and fuel market uncertainties for the potential deployment of an initial fleet of demonstration plants at the commercial scale. This paper presents the development of a systematic and comprehensive three-step methodological framework to assess the economic value of flexible alternatives in the design and operations of an IGCC-MR plant under the aforementioned sources of uncertainty. The main objective is to demonstrate the potential value enhancements stemming to the long-term economic performance of flexible IGCC-MR project investments, by managing the uncertainty associated with future environmental regulations and fuel costs. The paper provides an overview of promising design flexibility concepts for IGCC-MR power plants and focuses on operational and constructional flexibility. The operational flexibility is realized through the option of a temporary shutdown of the plant with considerations of regulatory and market uncertainties. This option reduces the probability of loss and the downside risk compared to the base case. The constructional flexibility considers installation of a Carbon Capture and Storage (CCS) unit in the plant under three different alternatives: 1) installing CCS in the initial construction phase, 2) retrofitting CCS at a later stage and 3) retrofitting CCS with pre-investment at a later stage. Monte Carlo simulations and financial analysis are used to demonstrate that the most economically advantageous flexibility option is to install CCS in the initial IGCC-MR construction phase.
\end{abstract}

Index Terms - computer simulation; decision making; largescale systems; systems analysis and design; systems engineering; risk analysis

This work was supported by the U.S. Department of Energy, Award No. DEFC26-07NT43058 \& DE-FE0004895, and by the National University of Singapore (NUS) Faculty Research Committee via MoE AcRF Tier 1 grants WBS R-266-000-061-133.

J. Zhang, M.-A. Cardin and S. K. K. Ng are with the Department of Industrial and Systems Engineering, National University of Singapore (e-mail:

juzheng.zhang@nus.edu.sg; macardin@nus.edu.sg;

simonkknghk@gmail.com).

N. Kazantzis and Y. H. Ma are with the Center for Inorganic Membranes, Department of Chemical Engineering, Worcester Polytechnic Institute, Massachusetts, USA (e-mail: nikolas@wpi.edu; yhma@wpi.edu)

\section{INTRODUCTION}

$\mathrm{E}$ LECTRICITY consumption in the United States is expected to increase from 3,877 billion kilowatt-hours $(\mathrm{kWh})$ in 2010 to over 4,716 billion $\mathrm{kWh}$ in 2035 , a $22 \%$ increase [1]. Coal-fired power plants are expected to remain the dominant source of electricity due to their cost advantages and low technology risks. Currently, these power plants account for over $28 \%$ of global carbon dioxide $\left(\mathrm{CO}_{2}\right)$ emissions [2]. It is well recognized that the increasing amount of $\mathrm{CO}_{2}$ in the atmosphere represents a major contributor to climate change. To avoid irreversible damage, governments have designed policy responses (e.g. $\mathrm{CO}_{2}$ emissions permit trading schemes and/or carbon tax regimes [3]) to reduce carbon emissions from electric power systems.

A new promising technology option for electric power generation with a lower carbon intensity endowment is the Integrated Gasification Combined Cycle (IGCC) power plant [4] IGCC is a process system that allows the structural integration of a gasification unit with a standard combined cycle power component. After gasification coal or other solid or liquid feedstock (e.g. biomass, various oils, etc.) are converted into synthetic gas (also known as syngas), which is comprised predominantly of hydrogen $\left(\mathrm{H}_{2}\right)$ and carbon monoxide (CO). The combustible syngas is first treated for the removal of sulfur dioxide $\left(\mathrm{SO}_{2}\right)$, nitric oxide, mercury and particular matter and then used in a gas turbine to produce electricity, whereas the assorted exhaust heat is used to generate steam for a second-generation cycle through a steam turbine. It should be emphasized that the gasification process system and the combined cycle power block are associated with mature technologies and have been broadly utilized in the petrochemical, chemical processing industries as well as for power generation (electricity production from natural gas).

IGCC power plants display comparable efficiency levels to coal-fired power plants and superior environmental performance (in terms of both $\mathrm{CO}_{2}$ and pollutant emissions), which can be attained at a lower cost when the integration of a Carbon Capture and Storage (CCS) unit is pursued [4, 5]. In this paper, the integration of membrane reactor technology into an IGCC power plant (IGCC-MR) is considered. Specifically, Pd-based composite membrane reactor technology [6] offers the option of combining in a single step and on a single process unit (a membrane reactor module serving as the technology platform) the water-gas-shift reaction that plays such a vital role in the enhanced 
environmental performance of IGCC with the production of high-purity hydrogen as well as high-quality separation of $\mathrm{CO}_{2}$ from the reaction products in coal-fired power plants. The replacement of multiple process units found in a traditional IGCC setting by a single unit such as the membrane reactor module is obviously advantageous from a process economic standpoint [6-8]. The high-quality separation of $\mathrm{CO}_{2}$ from high-purity hydrogen co-produced with electricity within the IGCC-MR context renders this option quite attractive [9].

However, IGCC power plants require significant capital investment and exhibit more challenging operational characteristics as well as maintenance requirements. The Energy Information Agency (EIA) calculates that the overnight capital cost is $\$ 2,505 / \mathrm{kW}$ for IGCC without $\mathrm{CO}_{2}$ capture and $\$ 3,568 / \mathrm{kW}$ for IGCC with $\mathrm{CO}_{2}$ capture compared to $\$ 2,010 / \mathrm{kW}$ for advanced pulverized coal plants without $\mathrm{CO}_{2}$ capture [1]. It becomes evident that given uncertainty over the future carbon tax regime and rate, as well as electricity price and hydrogen price, it may not be worth operating IGCC-MR plants under some scenarios. In light of the long lifecycle of infrastructure components and significant upfront costs associated with energy projects of such a scale, it is important to carefully assess and simulate the main irreducible uncertainty sources affecting the future economic performance of IGCC-MR power plants, and therefore inform and facilitate the possible deployment of an initial set of demonstration projects of this new advanced technology.

The present study evaluates the economic value of flexible alternatives in the design and operation of an IGCC-MR plant under the aforementioned sources of uncertainty. The main objective is to demonstrate the potential value enhancement prospects related to the long-term economic performance of IGCC-MR project investments by managing the uncertainty associated with future environmental regulations and fuel costs. By assessing the economic value of flexibility and real options in plant design and operation, this paper identifies and evaluates a set of flexibility options that are economically justified and thus help the IGCC-MR system maintain a highlevel of economic performance as uncertainties get progressively resolved. Another objective is the development and evaluation of a set of flexible decision rules (e.g. pertaining to the operating mode of CCS and the type of fuel feed while responding to future developments in the regulatory regime, fuel and hydrogen markets) that will help plant managers to adopt design real options, and advantageously exercise them in a world fraught with uncertainty. Decision rules determine the trigger points, or criteria that must fulfilled in order to exercise the flexibility, based on observations of uncertainty drivers.

This study is the first to provide a decision-support framework to design and manage IGCC-MR plants under uncertainty by exploiting ideas of flexibility. It relies on the use of decision rules, which differs from typical real options analysis, since it aims at emulating directly the decisions made by the plant operators. This analysis enables the management team to characterize and eventually enhance the IGCC-MR plant's adaptability to the main uncertainty sources such as environmental regulations and fuel costs over its long lifecycle. It is shown that explicitly recognizing flexibility can help improve the lifecycle economic performance of such promising advanced clean energy technology, and a sound justification basis to policy and decision-makers for the creative development of the requisite demonstration and adoption incentives.

This paper is organized as follows: Section II describes the three-step methodology to evaluate value-enhancing flexible design real options. It illustrates the application to the problem of identifying and characterizing flexible design options in IGCC-MR power plants. Section III encompasses the main findings, results of the analysis, and a relevant discussion. Section IV concludes by discussing limitations and opportunities for future work.

\section{ANALYSIS}

A three-step methodology based on decision rules and Monte Carlo simulations is applied to evaluate the economic performance of IGCC-MR under uncertainty and the assorted value-enhancing prospects induced by a set of flexibility options in its design.

\section{A. Baseline DCF Model}

A DCF model for evaluating the design of IGCC-MR power plants was developed in Excel® based on the following assumptions:

1. The IGCC-MR plant is assumed to be operational for 40 years and configured with an entrained flow gasifier, which is the most common IGCC design option at commercial scale [7].

2. This analysis evaluates the costs of equipment based on the cost figures from the General Electric Energy (GEE) IGCC with $\mathrm{CO}_{2}$ capture (traditional PBR plant 4) in the DOE/NTEL report [10]. The costs of equipment are calculated using the Marshal \& Swift (M\&S) equipment cost index [11]. Estimates derived from the M\&S indexes are accurate for a period of 10 years [12].

3. Selling electricity gives rise to the only revenue stream by operating the IGCC MR plant. Annual revenue is calculated as follows:

$$
A I_{t}=\lambda_{t}^{e l e c} \cdot C F_{t} \cdot 24 \cdot 365 \cdot P_{t}
$$

where $A I_{t}$ is the annual income at year $t ; \lambda_{t}^{\text {elec }}$ is the electricity price at year $t$; $C F_{t}$ is the capacity factor at year $t$; $P_{t}$ is the hourly energy output at year $t$.

4. The electricity price is based on historical trends and data and is not altered by the effect of carbon taxes.

5. The total operating costs are the sum of the following costs:

$$
O C_{t}=F C_{t}+O M C_{t}+I P T_{t}+T S C_{t}
$$

where $O C_{t}$ is the total operating cost at year $t ; F C_{t}$ is the fuel cost at year $t ; O M C_{t}$ is the operating and maintenance cost at year $t ; I P T_{t}$ is the insurance and property tax at year $t ; T S C_{t}$ is the $\mathrm{CO}_{2}$ transportation and sequestration cost at 
year $t$.

6. The fuel cost is given by the following equation:

$$
F C_{t}=\lambda_{t}^{\text {coal }} \cdot C F_{t} \cdot 24 \cdot 365 \cdot S_{t}
$$

where $\lambda_{t}^{\text {coal }}$ is the coal price at year $t ; S_{t}$ is the hourly coal feed at year $t$.

7. A depreciation rate is assumed to follow the declining balance method [11] as shown below:

$$
\begin{gathered}
A V_{t}=\left(1-D R_{t}\right) A V_{t-1} \\
D V_{t}=A V_{t}-A V_{t-1}
\end{gathered}
$$

where $A V_{t}$ is the asset value at year $t ; D R_{t}$ is the depreciation rate at year $t ; D V_{t}$ is the depreciation value at year $t$.

8. By considering the depreciated asset value, the insurance and property tax at year $t\left(I P T_{t}\right)$ is computed as follows:

$$
I P T_{t}=I P T R_{t} A V_{t-1}
$$

where $I P T R_{t}$ is the insurance and property tax rate at year $t$

9. The plant is built in 2013 and the carbon tax will be levied starting from \$10 in 2017 with an expected annual growth rate of $3 \%$ afterwards. The carbon tax at year $t$ is calculated as follows:

$$
C T_{t}=C T R_{t} \cdot E_{t}^{C O 2}
$$

where $C T_{t}$ is the carbon tax at year $t ; C T R_{t}$ is the carbon tax rate at year $t ; E_{t}^{C O 2}$ is the emission of carbon dioxide at year $t$.

10. Taking into account income tax and the above set of equations (3)-(9), the annual cash flow $\left(A C F_{t}\right)$ is calculated as follows:

$$
A C F_{t}=\left(A I_{t}-O C_{t}\right)\left(1-I T_{t}\right)+D V_{t}-C T_{t}
$$

where $I T_{t}$ is the income tax at year $t$.

11. In view of the higher risk associated with the IGCC-MR technology - it has not been demonstrated at commercial scales yet - the assorted higher maintenance requirements and technical complexities, the nominal discount rate was set at $9 \%$ in the DCF analysis. This rate is comparable to the one used for IGCC baseline plants. The real discount rate was calculated by considering the inflation rate.

12. Given the pertinent technical specifications [7], a $98 \% \mathrm{CO}_{2}$ separation quality level is considered.

13. There are 2,000 Monte Carlo iterations (scenario generation) in each run.

14. All input parameters are summarized in Table A.1.

\section{B. Uncertainty Analysis}

There are a number of uncertain parameters associated with the IGCC-MR plant's economic performance (e.g. $\mathrm{CO}_{2}$ tax, $\mathrm{CO}_{2}$ tax growth rate, plant capacity factor, inflation rate, electricity demand, electricity price, hydrogen price, hourly wage, Pd-price, coal price, membrane life time and etc.). Carbon taxes and coal prices are the ones most likely to affect economic performance, and will be described as follows:

\section{1) Carbon taxes}

To generate a realistic $\mathrm{CO}_{2}$ tax scenario, this paper mainly considers the body of literature pertaining to $\mathrm{CO}_{2}$ emission permit trading schemes considered in the United States and Europe. In general, there are two key variables considered in this scenario, namely, the initial $\mathrm{CO}_{2}$ tax and its growth rate.

$\mathrm{CO}_{2}$ emission permits have been traded in Europe under the European Union Emissions Trading Scheme (ETS) since 2005. The carbon price was at an average of $\$ 10.80 / \mathrm{tCO}_{2}$ from September 2011 to September 2012. Considering the impact of the financial crisis on carbon price and the discrepancy between EU and US carbon prices, the most likely value of a future carbon tax is assumed at $\$ 10 / \mathrm{tCO}_{2}$. The maximum value is assumed to be $\$ 50 / \mathrm{tCO}_{2}$, or the pre-crisis peak of carbon price in the European Union. The minimum value is $\$ 1 / \mathrm{tCO}_{2}$. The uncertain initial carbon tax is modeled using a triangular distribution based on the above values.

For the carbon tax growth rate, a Geometric Brownian Motion (GBM) model is adopted:

$$
\operatorname{CTGR}_{t}=\mu \cdot \Delta t+\sigma \cdot \varepsilon \cdot \sqrt{\Delta t}
$$

Here $C T G R_{t}$ is the carbon tax growth rate at year $t ; \mu$ is the drift (assumed to be 3\% [13]); $\sigma$ is the volatility (assumed to be $3 \%$ by taking into account the existing historical data of $\mathrm{CO}_{2}$ emission permits [14]); $\varepsilon$ captures the Wiener process based on a standard normal distribution; $\Delta t$ is the time step (equal to 1 year in this study).

\section{2) Coal Prices}

According to DOE [10], Illinois \#6 coal represents the favored feed for IGCC plants but its price history is not released by the EIA for reasons of IP protection. Here, annual coal prices from EIA are considered [1]. The analysis conducted could be easily modified if the Illinois \#6 coal price history were made available. By using regression analysis, the drift and volatility of annual coal prices from years 2001 to 2011 were found at $8.52 \%$ and $4.85 \%$, respectively. The uncertain annual coal price growth rate is modeled using similar GBM assumptions as above.

\section{Flexibility Analysis}

Flexibility options can be classified as options "on" or "in" engineering systems [15]. Flexibility "on" systems refers to managerial flexibility such as abandoning operation, changing capacity, deferring until favorable market conditions develop, etc. Flexibility "in" systems refers to the change of design components to enable flexibility. Here, three flexibility options are considered: 1) fuel-related ("on"), 2) operational (“on"), and 3) constructional ("in"). Such strategies should contribute to improve the economic performance of an IGCCMR power plant in an uncertain regulatory and market environment. These real options were generated from expert elicitation and advice, by exploring the IGCC literature, using systematic concept generation techniques, and also 
considering standard strategies from the literature on real options and flexibility in engineering design [15-17]

\section{1) Fuel Flexibility}

IGCC technology has the potential to handle a wide range of primary fuels such as coal, biomass, waste, petroleum coke, refinery residues, as well as a blend of these fuels. It possesses a proven ability to co-fire syngas from primary fuels with secondary fuels such as natural gas - as first adopted in 1996 by the Texaco EI Dorado IGCC plant in Kansas. Syngas provides one third of the thermal input while natural gas provides the remaining two thirds. Power availability of $97 \%$ has been achieved during the plant operations. By 2000, there were 19 General Electric gas turbines operating on a mix of coal, petroleum coke and other low heating value fuels [18].

The fuel flexibility decision rule ensures that an IGCC power plant can selectively use a few types of fuels depending on their prices (and developments in their respective markets) to effectively manage the uncertainty of fuel prices and availability.

\section{2) Operational Flexibility}

Operational flexibility is motivated by uncertain power demand patterns and the future state of environmental regulations. For a reduction in $\mathrm{GHG}$ emissions, renewable energy sources are expected to gradually replace a percentage of the current fossil fuel used in power generation. However, renewable energy sources such as wind and solar cannot produce stable output due to the intermittency induced by changes in weather conditions. Within such a context, IGCC power plants would still be needed to reliably compensate for the intermittent energy output of renewables.

Two flexible operating modes are considered. The first one is operating the plant under partial load (i.e. producing a fraction of the full load output), and the second is to shutdown and start-up periodically in response to the uncertain environment. The partial load operation is deemed impractical because it imposes a penalty on plant efficiency and results in a relatively high GHG emission rate per unit of electricity generated. The periodic shutdown and start-up (involving particularly the operation of the CCS component unit) option is more meaningful. The decision rule models that logic that when emission permit or carbon tax prices are high or renewables produce high outputs, the plant may be dormant. In opposite conditions, the plant operation becomes favorable.

The main concerns regarding the periodic shutdown and start-up modes are the operation reliability and the relatively high operating cost of start-up. The start-up time is also a key factor. A shorter start-up time implies lower fuel consumption rates during start-up and higher start-up efficiency, resulting in significant savings in fuel and $\mathrm{CO}_{2}$ emissions costs. It has been convincingly demonstrated that Siemens FACYTM provides an economic and technically viable solution for fast shutdown and start-up [19]: de-loading from $100 \%$ to $55 \%$ is achieved within 6 seconds and start-up takes less than 30 minutes. Siemens demonstrated that nightly shut downs saved 360 ton $\mathrm{CO}_{2}$ per night and therefore mitigated the risk of a high carbon tax [19].

\section{3) Constructional Flexibility}

The phased construction concept can be applied to an IGCC-MR plant $[15,20]$. The plant may initially be built starting with a natural gas combined cycle and allowing space for future development. Later, if coal prices are competitive or production of by-products from syngas becomes economically attractive, coal gasification and syngas treatment components could be added. If a carbon tax is levied, CCS could be installed to remove $\mathrm{CO}_{2}$. Flexible phased construction requires pre-investment to minimize operation disruption and capital expenditures when future development is carried out.

There are currently two main concepts of technology for $\mathrm{CO}_{2}$ capture, namely pre-combustion capture and postcombustion capture. Pre-combustion capture technology removes $\mathrm{CO}_{2}$ before the syngas is combusted in the gas turbine. Therefore, the combusted syngas contains mainly hydrogen, generating also an opportunity for extra-purity hydrogen production. As most $\mathrm{CO}_{2}$ and carbon composites are removed, the gas turbine does not need to be designed to accommodate different compositions of $\mathrm{CO}_{2}, \mathrm{CO}$ and $\mathrm{H}_{2}$. Thus, the plant could use a wide range of fuels. Due to the relative small volume of syngas for $\mathrm{CO}_{2}$ cleaning, the capture level is guaranteed at more than $90 \%$ [21].

CCS operation takes place at the expense of energy that could have been used for electricity generation. Due to the operation of CCS, the capacity factor is assumed to drop from $80 \%$ to $75 \%$. The cost estimates of fuel, O\&M, $\mathrm{CO}_{2}$ emissions and $\mathrm{CO}_{2}$ transportation and sequestration are summarized in Table B.I, Appendix B.

If the carbon tax rate is high or grows fast, it may be economical to install and operate a CCS unit. Apart from the initial capital investment on carbon capture, each ton of $\mathrm{CO}_{2}$ incurs a transportation and sequestration cost of $\$ 10$ [22]. Capturing $\mathrm{CO}_{2}$ takes place at the expense of generating electricity, and therefore the net electricity output will be smaller for an IGCC-MR power plant with carbon capture than that without carbon capture. For comparison purposes, costs and revenues in the economic performance assessment framework are corrected for a common net output figure of 550 MWe amongst all operating modes and design possibilities (through plant component re-sizing) considered.

\section{RESUltS AND DISCUSSIONS}

Our analysis focuses on the quantitative evaluation of the flexible options to provide better guidance for decisionmaking. For each case, several sub-options are introduced, such as base case (BC), decision rules (DR), investment at later stage (LS), and with pre-investment (PI). For better readability, the cases are listed as follows:

Case 1: Operational Flexibility (i.e. "ON" flexibility)

- Case 1-a (denoted by ON_BC) is a base case for an IGCC-MR plant without considering operational flexibility and CCS technology;

- Case 1-b (denoted by ON_DR) introduces the operational flexibility mentioned earlier with the consideration of switching decision rules;

Case 2: Constructional Flexibility (i.e. "IN") 
- $\quad$ Case 2-a (denoted by IN_BC) introduces CCS in the initial construction phase and assumes that it remains operational all the time throughout the plant's economic life.

- $\quad$ Case 2-b (denoted by IN_DR) introduces CCS in the initial construction phase and assumes that its operation is governed by decision rules in response to the state of the uncertain regulatory environment;

- Case 2-c (denoted by IN_DR_LS) introduces the option of plant retrofitting with a CCS unit at a later stage until favorable economic conditions arise in response to developments in the regulatory environment;

- Case 2-d (denoted by IN_DR_LS_PI) introduces the option of plant retrofitting with a $\bar{C} C S$ unit at a later stage when pre-investment took place for such a design accommodation until favorable economic conditions arise in response to developments in the regulatory and market environment ;

\section{A. Operational Flexibility}

Since this analysis focuses on a year-to-year operation, the formulated operational flexible option is to temporarily shut down the plant for a year in case of continuing economic loss. This is referred as ON_DR (Case 1-b) thereafter. The decision rule is to temporarily shut down the plant for a year if the cash flows for the previous two years are negative. The same decision rule is applied for all remaining years. If any one of the two previous years displays non-negative cash flow, the plant will remain open. The plant will be re-opened if the forecasted cash flows in any one of two previous years are positive. When the plant is closed in year $t-1$ and reopens in year $t$, an extra O\&M cost of $\$ 4.3$ million [13] will be incurred for starting up the plant in year $t$.

In a year when the plant is not operating, no revenue stream is generated. Therefore, any depreciation and the assorted depreciation tax shield will be delayed until the next operating year. Furthermore, the land rental is most likely specified in a long-term contract, and thus represents a sunk cost. According to corporate finance principles, this sunk cost should not affect short-term operation decisions [23]. The plant is assumed to dismiss its labor force during the shutdown period and not purchase any raw materials. Hence, no operating cost will be incurred. As a result, the plant generates a zero cash flow in a non-operating year, instead of operating at a potential loss.

There might be of course limitations on the zero operating cost assumption. The plant owners may still need to pay for worker layoff compensation and recruitment. Given the intractable complexities of labor relations and pertinent market issues, the associated costs are omitted in the present study.

The simulation results are summarized in Table I. The best results are highlighted in bold. The CDF plots in Fig. 1 show that the flexible case dominates the base case in all evaluation metrics, except for maximum value and VAG P95, for which both designs appear to exhibit similar economic behavior. Expected NPV (ENPV) changes from negative to positive by incorporating the operational flexibility option. Furthermore, the NPV profile becomes less spread in the flexible design case. ON_DR (Case 1-b) produces a $21 \%$ increase in value at risk (VAR) or $5^{\text {th }}$ percentile (P5), suggesting the possibility of a better management of downside risk. In most simulation runs, the operational flexibility option is exercised 4-8 times over the plant's lifetime, accounting for over $80 \%$ of the runs. This shows that flexibility adds value, and is used in several occasions for a significant number of samples.

TABLE I

SIMULATION RESULTS FOR OPERATIONAL FLEXIBILITY

\begin{tabular}{c|c|c|c}
\hline \hline & $\begin{array}{c}\text { Deterministic } \\
\text { case }\end{array}$ & $\begin{array}{c}\text { Case 1-a } \\
(\text { ON_BC })\end{array}$ & $\begin{array}{c}\text { Case 1-b } \\
(\text { ON_DR })\end{array}$ \\
\hline ENPV $(\$ \mathrm{M})$ & 669.2 & -67.5 & $\mathbf{2 4 1 . 1}$ \\
\hline Max $(\$ \mathrm{M})$ & N/A & $\mathbf{2 , 0 2 2 . 3}$ & $1,953.4$ \\
\hline Min $(\$ \mathrm{M})$ & N/A & $-5,230.7$ & $\mathbf{- 4 , 1 7 3 . 3}$ \\
\hline VAG P95 $(\$ \mathrm{M})$ & N/A & $\mathbf{1 , 6 5 9 . 7}$ & $1,647.1$ \\
\hline VAR P5 $(\$ \mathrm{M})$ & N/A & $-4,868.0$ & $\mathbf{- 3 , 8 6 6 . 9}$ \\
\hline $\begin{array}{c}\text { Standard } \\
\text { Deviation }(\$ \mathrm{M})\end{array}$ & N/A & 992.0 & $\mathbf{7 8 3 . 5}$ \\
\hline $\begin{array}{c}\text { Probability of } \\
\text { Loss }(\$ \mathrm{M})\end{array}$ & N/A & $47 \%$ & $\mathbf{3 4 \%}$ \\
\hline \hline
\end{tabular}

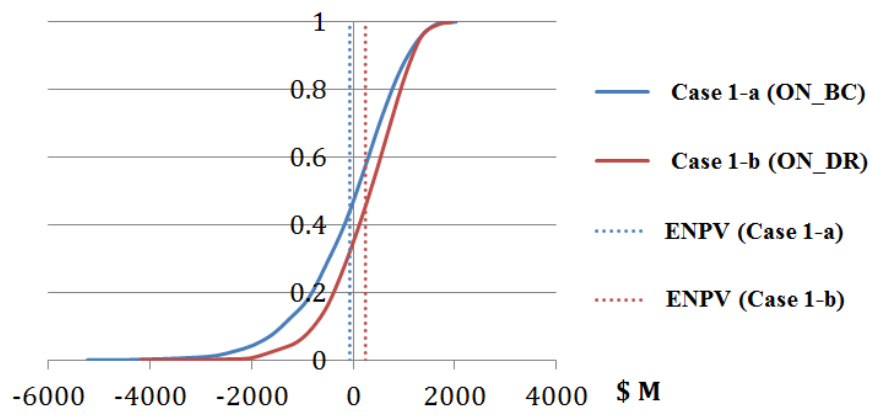

Fig. 1 CDF plots for ON_BC (Case 1-a) and ON_DR (Case 1-b)

\section{B. Constructional Flexibility - Inclusion of CCS Unit in the Design Phase}

Two flexible options, IN_BC (Case 2-a) and IN_DR (Case 2-b) are introduced in this section. Case 2-a introduces CCS in the initial construction phase and assumes that it remains operational all the time throughout the plant's economic life. Case 2-b includes the CCS unit in the design phase of the plant and the opportunity to be operational only when it becomes cost effective. Cost-effectiveness is determined when the CCS-relevant cost is lower than the amount paid for $\mathrm{CO}_{2}$ emission taxes in the previous two years (decision rule associated with exercising the constructional flexibility option). Within the above context, the CCS-relevant cost refers to the after-tax cost of the additional consumption of fuel, operation and maintenance cost, the $\mathrm{CO}_{2}$ transport and sequestration cost and the forgone electricity revenue due to the inevitable drop in the plant's capacity factor.

ON_BC (Case 1-a), IN_BC (Case 2-a) and IN_DR (Case 2b) are normalized to account for the same electricity output of 550 MWe (through appropriate component re-sizing in the respective designs and cost/revenue re-calculation) in order to ensure a fair comparison. In the analysis of Cases 2-a and 2-b, the capital investments are the same. This analysis assumes no additional capital cost associated with activating or cancelling the operation of the CCS unit because this is likely to be 
included into most plant designs for reliability, availability and maintenance purposes [24]. This assumption is in accordance with the assumption in Patino-Echeverri et al. [25].

Simulation results for ON_BC (Case 1-a), ON_DR (Case 1-b), IN_BC (Case 2-a), and IN_DR (Case 2-b) are summarized in Table II. The performed analysis introduces one degree of flexibility at a time to show how flexibility adds value incrementally. This approach reveals potential biases of the model more effectively than solely comparing the highly flexible case with the base case. Finally, all flexible cases are comparatively assessed against the base case as well.

The inflexible alternative IN_BC (Case 2-a) represents a better choice than the inflexible $\mathrm{ON}$ BC (Case 1-a), or even the flexible alternative ON_DR (Case 1-b) - except for Max NPV and P95. IN_BC (Case 2-a) is also cheaper. This shows that inclusion of CCS leads to a significant improvement on the ENPV-metric level, reduces the dispersion of the NPV profiles and mitigates the downside risk. The plant owner, however, needs to make a tradeoff between the gains and the penalty on upside opportunities.

TABLE II

SiMULATION RESUltS SUMMARY FOR CASES 1-A, 1-B, 2-A AND 2-B

\begin{tabular}{c|c|c|c|c|c}
\hline \hline & $\begin{array}{c}\text { Determini } \\
\text { stic case }\end{array}$ & $\begin{array}{c}\text { Case 1-a } \\
(\text { ON_BC })\end{array}$ & $\begin{array}{c}\text { Case 1-b } \\
(\text { ON_DR })\end{array}$ & $\begin{array}{c}\text { Case 2-a } \\
(\text { IN_BC })\end{array}$ & $\begin{array}{c}\text { Case 2-b } \\
(\text { IN_DR })\end{array}$ \\
\hline ENPV (\$ M) & 669.2 & -67.5 & 241.1 & 254.1 & $\mathbf{5 4 1 . 8}$ \\
\hline Max $(\$ \mathrm{M})$ & N/A & $\mathbf{2 , 0 2 2 . 3}$ & $1,953.4$ & $1,358.0$ & $1,940.8$ \\
\hline Min (\$ M) & N/A & -5230.7 & $-4,173.3$ & $\mathbf{- 2 , 2 0 6 . 8}$ & $-2,731.6$ \\
\hline $\begin{array}{c}\text { VAG P95 (\$ } \\
\text { M) }\end{array}$ & N/A & $1,659.7$ & $1,647.1$ & $1,179.8$ & $\mathbf{1 , 7 0 7 . 2}$ \\
\hline $\begin{array}{c}\text { VAR P5 (\$ } \\
\text { M) }\end{array}$ & N/A & $-4,868.0$ & $-3,866.9$ & $\mathbf{- 2 , 0 2 8 . 5}$ & $-2,497.9$ \\
\hline $\begin{array}{c}\text { Standard } \\
\text { Deviation }(\$ \\
\text { M) }\end{array}$ & N/A & 992.0 & 783.5 & $\mathbf{4 6 1 . 0}$ & 489.9 \\
\hline $\begin{array}{c}\text { Probability of } \\
\text { Loss }\end{array}$ & N/A & $47 \%$ & $34 \%$ & $26 \%$ & $\mathbf{1 3 \%}$ \\
\hline \begin{tabular}{c} 
Capex $(\$$ M) \\
\hline \hline
\end{tabular} & $\mathbf{1 , 5 1 4}$ & $\mathbf{1 , 5 1 4}$ & $\mathbf{1 , 5 1 4}$ & 1,576 & 1,576 \\
\hline \hline
\end{tabular}

A comparison of IN_BC (Case 2-a) and IN_DR (Case 2-b) show how the operational flexibility of $\mathrm{CCS}^{-}$adds economic value to the plant operations (see Table II and Fig. 2). It can be inferred that the operational flexibility option increases the ENPV by $113 \%$ and the standard deviation by $6.3 \%$. However, as seen in Fig. 2, the increase in standard deviation is mainly due to the fact that the CDF profile in IN_BC (Case 2-a) stretches out to the positive side - arguably a good thing. IN DR (Case 2-b) significantly decreases the probability of loss from $26 \%$ to $13 \%$. However, VAR for IN DR is $24 \%$ lower than for IN_BC. Downside NPVs may correspond to high carbon tax scenarios. Since $100 \%$ carbon capture cannot be realized, the plant management needs to pay for carbon taxes even when CCS is running. High carbon taxes add burden to the plant and thus lead to smaller NPV values. In high carbon tax scenarios, Case 2-b appears to be disadvantageous compared to Case 2-a because the CCS unit should be operated immediately, however its operation is delayed by two years based on the decision rule. Thus, high costs are inevitably incurred.

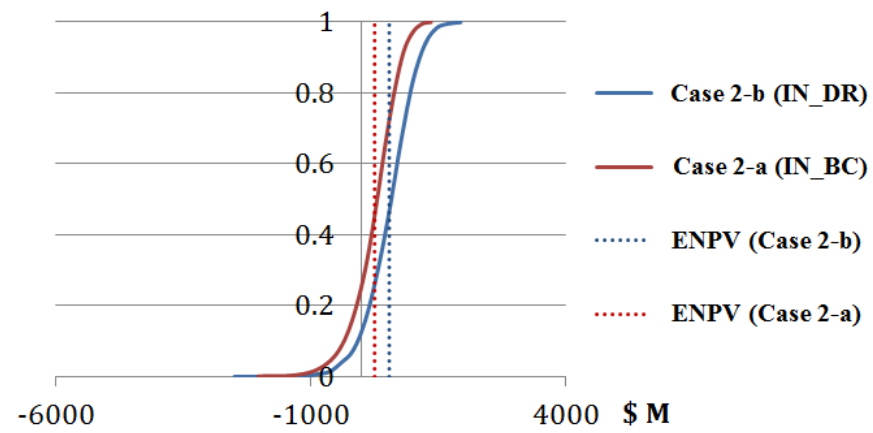

Fig. 2 CDF plots for IN_BC (Cases 2-a) and IN_DR (Case 2-b)

\section{Constructional Flexibility - Inclusion of CCS Unit at a Later Stage}

Within the context of this study, retrofitting an IGCC-MR plant means the integration of a CCS unit into the plant's structure at a later stage rather than at the design phase. It is motivated by the irreducible uncertainty in the regulatory regime involving $\mathrm{CO}_{2}$ emissions. The cost of retrofitting an IGCC-MR plant for $\mathrm{CO}_{2}$ capture is higher than the difference in the total plant costs between a green-field (i.e. not constrained by prior work) no-capture and capture plant for the following reasons:

- There are two separate construction phases, which require additional planning and contracting requirements.

- The layout of the plant may have to be modified to accommodate the $\mathrm{CO}_{2}$ conditioning and compression unit.

- The components of the plant may be mismatched after the retrofit, increasing the output de-rating of the plant after retrofit relative to a green-field capture plant.

Here, all three cases examined are endowed with the operational flexibility option for the CCS unit. IN DR (Case 2-b) includes a CCS unit in the initial construction phase, the same as in the previous subsection. IN_DR_LS (Case 2-c) involves the CCS-based retrofitting of the plant as described above. Finally, IN_DR_LS_PI (Case 2-d) considers plant retrofitting with pre-investment enabling the later accommodation of the CCS-unit into the IGCC-MR structure. Pre-investment can reduce the output de-rating occurring after retrofit. Within this context, both MIT [13] and EPRI [26] presented a bundle of pre-investment options for CCS retrofit. The studies advocate pre-investment strategies focused on the air separation unit and gasifier, which are designed with approximately $10 \%$ more capacity. The pre-investment cost figure was taken from the MIT study [13], and is $\$ 66.44 / \mathrm{kWe}$ in 2012 .

The output de-rating and net efficiency figures are also taken from the MIT study [13] and by using the comprehensive simulation model developed by Koc et al. [7]. Details are shown in Table B.I, Appendix B. Retrofit investment includes the retrofit cost and output de-rating cost. Also, retrofit costs are associated with the addition of the $\mathrm{CO}_{2}$ compression and conditioning units. The specific cost figures are taken from the US DOE [10]. The output de-rating cost is estimated by considering the building cost of a makeup plant to compensate for the output de-rating. It is equal to the product of the output de-rating and the overnight capital cost 
of a green-field IGCC plant with $\mathrm{CO}_{2}$ capture. The overnight capital cost estimates are also taken from the US DOE [10]. Comprehensive cost and performance summaries are presented in Table B.II in Appendix.

For both IN_DR_LS and IN_DR_LS_PI, the retrofit is pursued if during the previous two years the benefit of operating the plant with a CCS unit outweighs the assorted total cost ("decision rule"), i.e. if the following inequality holds true: savings on carbon tax $>$ (1-tax rate) $\mathrm{x}\left(\mathrm{CO}_{2}\right.$ transportation and sequestration costs + additional fuel costs + foregone electricity revenue due to capacity factor penalty + additional $O \& M$ costs).

Once the retrofit is complete, the retrofit cost will be counted in the IGCC's asset and entitled to depreciation from the next year on. Finally, the present value of total investment is the sum of initial investment and the present value of retrofit investment. The simulation results are summarized in Table III. The plots of the CDF profiles for these three cases are shown in Fig. 3.

TABLE III

SIMULATION RESULTS SUMMARY FOR CASES 4-6

\begin{tabular}{l|l|l|l|l}
\hline \hline & $\begin{array}{l}\text { IN_DR } \\
(\text { Case 2-b) }\end{array}$ & $\begin{array}{l}\text { IN_DR_LS } \\
(\text { Case 2-c) }\end{array}$ & $\begin{array}{l}\text { IN_DR_LS } \\
\text { PI (Case 2-d) }\end{array}$ & $\begin{array}{l}\text { Improvement } \\
\text { by pre- } \\
\text { investment }\end{array}$ \\
\hline Mean (\$ M) & $\mathbf{5 4 1 . 4}$ & 338.0 & 357.6 & $6 \%$ \\
\hline Max (\$ M) & $1,895.3$ & $\mathbf{1 , 9 2 8 . 3}$ & $1,868.5$ & $-3 \%$ \\
\hline Min (\$ M) & $\mathbf{- 1 , 3 7 0 . 4}$ & $-1,992.1$ & $-1,492.3$ & $25 \%$ \\
\hline $\begin{array}{l}\text { Value at Gain } \\
\text { 95\% (\$ M) }\end{array}$ & $1,732.0$ & $\mathbf{1 , 7 3 2 . 3}$ & $1,700.5$ & $-2 \%$ \\
\hline $\begin{array}{l}\text { Value at Risk } \\
5 \%(\$ \text { M) }\end{array}$ & $\mathbf{- 1 , 2 0 7 . 1}$ & $-1,796.1$ & $-1,324.3$ & $26 \%$ \\
\hline $\begin{array}{l}\text { Standard } \\
\text { Deviation }(\$ \\
\text { M) }\end{array}$ & $\mathbf{4 8 6 . 2}$ & 502.9 & 500.1 & $-1 \%$ \\
\hline $\begin{array}{l}\text { Probability of } \\
\text { Loss }\end{array}$ & $\mathbf{1 4 \%}$ & $24 \%$ & $23 \%$ & $-1 \%$ \\
\hline Capex (\$ M) & 1,576 & $\mathbf{1 , 5 1 4}$ & 1,551 & $3 \%$ \\
\hline $\begin{array}{l}\text { PV(Capital } \\
\text { investment) }\end{array}$ & $\mathbf{1 , 5 7 6}$ & 1776.0 & $1,738.8$ & $-2 \%$ \\
\hline $\begin{array}{l}\text { Year of } \\
\text { Retrofit }\end{array}$ & N/A & 12 & 12 & N/A \\
\hline \hline
\end{tabular}

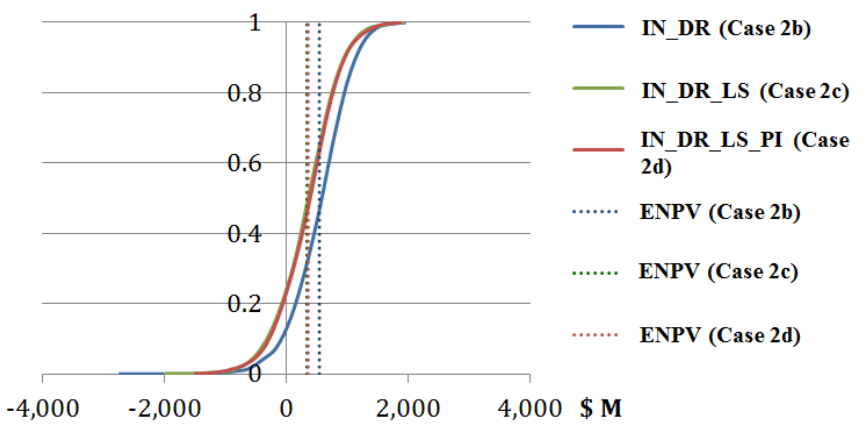

Fig. 3 CDF plots for IN_DR (Cases 2-b), IN_DR_LS (Case 2-c) and IN_DR_LS_PI (Case 2-d)

IN DR (Case 2-b) still generates the highest ENPV, significantly larger than the retrofit cases. IN DR also results in a less spread NPV profile and a smaller probability of loss.

Although the initial capital investment in IN_DR is higher than that in IN_DR_LS (Case 2-c) and IN_DR_LS_PI (Case 2-d), IN_DR has a smaller PV (Capital investment). On the other hand, IN_DR_LS outperforms the other two design alternatives in terms of maximum value and VAG. This corresponds to the scenarios where CCS is undesirable or only desired when the plant approaches the end of its lifetime. The present value of retrofitting is either zero or very small after heavy discount. In these scenarios, IN_DR_LS appears clearly more favorable than IN_DR and IN_DR_LS_PI, both of which encompass some investment in the design phase. However, the NPV profile for IN_DR_LS is the most spreadout (i.e. more volatility and risk) and the ENPV for IN_DR_LS is the smallest. Thus the overall performance of IN_DR_LS is not satisfactory. IN_DR_LS_PI is not the best performer in terms of any evaluation metric. However, if a plant owner decides to delay the integration of the CCS unit, then the pre-investment option boosts expected performance and provides insurance over unfavorable scenarios.

The present study holds a conservative stance on the carbon tax forecast and the stringency of the associated regulatory regime. This consideration should favor delaying the installation of the CCS unit in an IGCC-MR power plant. However, the results derived still show that IN_DR (Case 2-b) represents the best design alternative to handle uncertainty. For a more aggressive/stringent carbon tax policy, IN_DR (Case 2-b) would have an even more appealing NPV profile outperforming IN_DR_LS (Case 2-c) and IN_DR_LS_PI (Case 2-d) by a considerable margin.

\section{CONCLUSIONS}

This paper proposes and evaluates flexible design alternatives for an IGCC-MR power plant that enhance overall economic performance by minimizing downside risks while capitalizing on upside opportunities. It enables advantageous adaptations to uncertain $\mathrm{CO}_{2}$ emission regulations and fuel prices. A systematic three-step methodology is applied to evaluate flexibility options based on fuel, operational and a constructional strategies for the design of an IGCC-MR power plant. The results show that installing a Carbon Capture and Storage (CCS) unit at the design phase is the most flexible and economical option by exhibiting the lowest downside risk (at least $70 \%$ improvement compared to the base case) and the highest expected net present value (ENPV). The goal of this study is to help plant managers and operators to incorporate better policies and technological flexibility options in their planning stages, and determine the best planning and operating strategies in the presence of irreducible uncertainty.

The present work is constrained by certain limitations that help trace future research opportunities. First, a stochastic demand model for electricity could be developed as a modification of the proposed analytical framework to allow pure hydrogen sales in pertinent markets concurrently with sales of electricity. Second, the effect of a carbon tax (or a cap-and-trade scheme) on electricity price could be also studied, offering an opportunity for better understanding of its effects, and incorporated into the proposed framework as an uncertainty driver. Third, stochastic programming could be 
used to identify the better parameter values governing the flexibility decision rules. All such work is currently under way.

\section{APPENDIX}

\section{A. DCF model formulation}

TABLE A.I ECONOMIC PARAMETERS IN DCF MODEL FORMULATION

\begin{tabular}{l|l|l}
\hline \hline Parameter & $\begin{array}{l}\text { Mathematic } \\
\text { Expression }\end{array}$ & Value \\
\hline Plant life [years] & $L$ & 40 \\
\hline Tax rate & $T$ & $40 \%$ \\
\hline Depreciation accelerator & $D A$ & $30 \%$ \\
\hline Insurance and property tax rate & $I P T$ & $1.78 \%$ \\
\hline $\begin{array}{l}\mathrm{CO}_{2} \text { tax (\$/ tonnes, starts in the } \\
\text { fifth operating year) }\end{array}$ & $C T$ & 10 \\
\hline $\begin{array}{l}\text { Expected CO2 tax growth rate } \\
{[5]}\end{array}$ & $\mu^{C T}$ & $3 \%$ \\
\hline $\begin{array}{l}\mathrm{CO} 2 \text { transportation \& } \\
\text { sequestration cost }\left(\$ / \mathrm{t} \mathrm{CO}_{2}\right)[22]\end{array}$ & $T S C$ & 10 \\
\hline Nominal discount rate & $r$ & $9 \%$ \\
\hline Inflation rate & $\pi$ & $2.5 \%$ \\
\hline $\begin{array}{l}\text { Electricity selling price } \\
\text { [cents/kWh] }\end{array}$ & $\lambda_{t}^{\text {elec }}$ & 16.8 \\
\hline Plant capacity factor & $C F$ & $80 \%$ \\
\hline \hline
\end{tabular}

\section{B. Retrofit Performance and Cost Estimates}

TABLE B.I PERFORMANCE CHARACTERISTICS OF EVALUATED CASES BEFORE AND AFTER RETROFIT

\begin{tabular}{l|ll}
\hline \hline Parameters & IGCC MR Plant & $\begin{array}{l}\text { IGCC MR Plant } \\
\text { with Pre-investment }\end{array}$ \\
\hline Before retrofit & & \\
Output(MWe) & 550 & 550 \\
Efficiency (\% HHV) & $33.5 \%$ & $33.5 \%$ \\
$\mathrm{CO}_{2}$ emission (t/MWh) & 0.89 & 0.89 \\
\hline After retrofit & & \\
Output de-rating (\%) & $17 \%$ & $12.3 \%$ \\
Output(MWe) & 457 & 482 \\
Efficiency (\%, HHV) & $30.1 \%$ & $30.1 \%$ \\
$\mathrm{CO}_{2}$ emissions & 0.02 & 0.02 \\
$(\mathrm{t} / \mathrm{MWh})$ & & 0.98 \\
$\mathrm{CO}_{2}$ captured (t/MWh) & 0.98 & \\
\hline \hline
\end{tabular}

TABLE B.II MODEL INPUTS

\begin{tabular}{|c|c|c|}
\hline Parameters & IGCC MR Plant & $\begin{array}{l}\text { IGCC MR Plant } \\
\text { with pre-investment }\end{array}$ \\
\hline $\begin{array}{l}\text { Investment costs } \\
\text { Initial investment (M \$) } \\
\text { Retrofit and makeup } \\
\text { investment (M \$) }\end{array}$ & $\begin{array}{l}1514 \\
378\end{array}$ & $\begin{array}{l}1551 \\
288\end{array}$ \\
\hline $\begin{array}{l}\text { Before retrofit } \\
\text { Fuel Consumption (M ton) } \\
\text { O \& M costs (M \$/yr) } \\
\text { (excludes carbon tax) }\end{array}$ & $\begin{array}{l}1.53 \\
88\end{array}$ & $\begin{array}{l}1.53 \\
88\end{array}$ \\
\hline $\mathrm{CO}_{2}$ emissions $(\mathrm{MT} / \mathrm{yr})$ & 4.3 & 4.3 \\
\hline \multicolumn{3}{|l|}{ After retrofit } \\
\hline $\begin{array}{l}\text { Fuel Consumption (M ton) } \\
\text { O\&M costs (M\$/yr) } \\
\mathrm{CO}_{2} \text { emissions (MT/yr) } \\
\mathrm{CO}_{2} \text { sequestered (MT/yr) }\end{array}$ & $\begin{array}{l}1.60 \\
107 \\
0.1 \\
4.7\end{array}$ & $\begin{array}{l}1.60 \\
107 \\
0.1 \\
4.7\end{array}$ \\
\hline
\end{tabular}

\section{REFERENCES}

[1] Energy Information Agency. (2012). Annual Energy Outlook 2012 with Projections to 2035. Available: http://www.eia.gov/forecasts/aeo/pdf/0383(2012).pdf

[2] International Energy Agency. (2011). Power Generation from Coal: Measureing and Reporting Efficiency Performance and CO2 emissions. Available:

http://www.iea.org/ciab/papers/power generation from coal.pdf

[3] Exxon Mobil, "The Outlook for Energy: A View to 2040," 2012.
[4] W. G. Rosenberg, D. C. Alpern, and M. R. Walker, Deploying IGCC in this Decade with 3 Party Covenant Financing: Belfer Center for Science and International Affairs, John F. Kennedy School of Government, Harvard University, 2004.

[5] M. C. Bohm, H. J. Herzog, J. E. Parsons, and R. C. Sekar, "Capture-ready coal plants-Options, technologies and economics," International Journal of Greenhouse Gas Control, vol. 1, pp. 113-120, 2007.

[6] R. Koc, "Technical and Economic Performance Assessment of Pd/Alloy Membrane Reactor Technology Options in the Presence of Uncertainty," $\mathrm{PhD}$, Chemical Engineering, Worcester Poly. Inst., 2012.

[7] R. Koc, N. K. Kazantzis, W. J. Nuttall, and Y. H. Ma, "Economic assessment of inherently safe membrane reactor technology options integrated into IGCC power plants," Process Safety and Environmental Protection, vol. 90, pp. 436-450, 2012.

[8] C. A. Scholes, K. H. Smith, S. E. Kentish, and G. W. Stevens, "CO2 capture from pre-combustion processes-Strategies for membrane gas separation," International Journal of Greenhouse Gas Control, vol. 4, pp. 739-755, 2010.

[9] T. N. Veziroglu and F. Barbir, "Hydrogen energy technologies," Emerging Technology Series, prepared for the United Nations Industrial Development Organization, Vienna, 1998.

[10]J. L. Haslbeck, N. J. Kuehn, E. G. Lewis, L. L. Pinkerton, J. Simpson, M J. Turner, E. Varghese, and M. C. Woods. (2010, Cost and performance baseline for fossil energy plants volume 1: Bituminous coal and natural gas to electricity. Available: http://www.netl.doe.gov/energyanalyses/pubs/BitBase FinRep Rev2.pdf

[11] Marshall And Swift Cost Index. (2010). Available: http://www.chedigital.com/che/201001?pg=90 - pg90

[12] M. S. Peters and K. D. Timmerhaus, Plant design and economics for chemical engineers. USA: McGraw Hill, Inc., 1991.

[13]M. C. Bohm, "Capture-Ready Oower Plants-Options, Technologies and Economics," Master of Science in Technology and Policy, Massachusetts Institute of Technology, Cambridge, MA, United States, 2006.

[14]Regional Greenhouse Gas Initiative (RGGI). (2012). Available: http://www.rggi.org/market/co2 auctions/results

[15]R. de Neufville and S. Scholtes, Flexibility In Engineering Design. Cambridge, MA, United States: MIT Press, 2011.

[16]M.-A. Cardin, G. L. Kolfschoten, D. D. Frey, R. Neufville, O. L. Weck, and D. M. Geltner, "Empirical Evaluation of Procedures to Generate Flexibility in Engineering Systems and Improve Lifecycle Performance," Research in Engineering Design, vol. 24, pp. 277-295, 2013.

[17]L. Trigeorgis, Real Options. Cambridge, MA, United States: MIT Press, 1996

[18]R. D. Brdar and R. M. Jones, "GE IGCC technology and experience with advanced gas turbines," ger-4207, GE Power Systems, Schenectady, NY, vol. 10,2000 .

[19]A. Pickard and G. Meinecke, "The Future Role of Fossil Power Generation," Siemens AG, Munich, 2011.

[20]M.-A. Cardin, "Enabling Flexibility in Engineering Systems: A Taxonomy of Procedures and a Design Framework," ASME Journal of Mechanical Design, vol. 136, 2014.

[21] International Energy Agency. (2013, Global Action to Advance Carbon Capture and Storage. Available: http://www.iea.org/publications/freepublications/publication/CCS Annex .pdf

[22]N. Holt, "Preliminary economics of SCPC \& IGCC with CO 2 capture and storage," in Second International Freiberg Conference on IGCC and XtL Technologies, Freiberg, Germany (May 2007), 2007.

[23]C. Chen and E. S. Rubin, "CO2 control technology effects on IGCC plant performance and cost," Energy Policy, vol. 37, pp. 915-924, 2009.

[24]H. Chalmers, M. Lucquiaud, J. Gibbins, and M. Leach, "Flexible operation of coal fired power plants with postcombustion capture of carbon dioxide," Journal of Environmental Engineering, vol. 135, pp. 449-458, 2009.

[25]D. Patino-Echeverri and D. C. Hoppock, "Reducing the average cost of $\mathrm{CO} 2$ capture by shutting-down the capture plant at times of high electricity prices," International Journal of Greenhouse Gas Control, vol. 9, pp. 410-418, 2012.

[26] Electric Power Research Institute. (2012, Design Options for Enhancing IGCC Flexible Operations Performance and Economics. Available: http://www.epri.com/abstracts/Pages/ProductAbstract.aspx?ProductId=00 0000003002001052 